


\title{
Antecedentes sobre la relación histórica centralismo y descentralización en Chile*
}

\author{
Montecinos, Egon ${ }^{\star *}$
}

\section{Resumen}

El objetivo de este trabajo es revisar los principales intentos por descentralizar el Estado Chileno ocurridos desde 1810 hasta la fecha. A partir de esta revisión el artículo se propone explicar el actual carácter más administrativo que político de la descentralización. La revisión se realizó usando técnicas documentales de revisión bibliográfica en documentos y literatura especializada. El principal resultado de esta revisión es que antes de 1925 las demandas por descentralizar al país tenían un carácter más político y provenían de movimientos federalistas que demandaban al gobierno central una mayor distribución del poder político. Por su parte, a partir de 1925 se inició un proceso de descentralización o desconcentración de funciones que nace desde el propio Estado, el cual adopta un carácter más administrativo y se utiliza como estrategia para fortalecer el proceso de modernización y desarrollo económico del país.

Palabras clave: Descentralización, centralismo, estado chileno, constitución, antecedentes históricos.

\section{Antecedents in the Historical Relation Between Centralism and Decentralization in Chile}

\author{
Abstract \\ The purpose of this paper is to review the principal attempts at de-centralizing the Chilean gov- \\ ernment that occurred from 1810 up until the present. Based on this review we hope to explain the \\ present more administrative and less political character of the same. Documentary and bibliographi-

\section{Recibido: 05-01-12. Aceptado: 05-06-20} \\ * $\quad$ Agradezco sinceramente los comentarios realizados a este trabajo por los tres dictaminadores \\ anónimos. Este trabajo forma parte del capítulo histórico de la tesis para optar al grado de doctor \\ en ciencia política en Flacso-México, titulada: "Descentralización e innovación municipal en Chi- \\ le: limitantes del diseño institucional para una gestión municipal participativa y democrática". \\ ** Profesor Investigador del Centro de Estudios del Desarrollo Regional y Local (CEDER) de la \\ Universidad de Los Lagos, Osorno - Chile. Es Trabajador Social, Magíster en Ciencias Socia- \\ les, Doctor (@) en Ciencia Política por FLACSO-MEXICO. Dirección: Lord Cochrane \#1225, \\ Osorno (Chile). Fono-Fax: (56-64) 333583. \\ E-mail: egonelier@hotmail.com; egon@flacso.edu.mx; emontecinos@ulagos.cl
}



Montecinos, Egon

cal review of specialized literature was employed. The principal result of this review is that before 1925 , the demands for de-centralization of the country had a more political character based on the federalist movements that demanded on the part of central government greater distribution of political power. After 1925, the process of de-centralization and de-concentration of governmental functions began, motivated by the government itself, which adopted a more administrative character and utilized it as a strategy for strengthen the modernization process and the economic development of the country.

Key words: Decentralization, centralism, the Chilean state, constitution, historical antecedents.

\section{Introducción}

Diversos pueden ser los intentos para descentralizar un Estado, estos van desde las propuestas eminentemente radicales que afectan la integridad misma del sistema de gobierno ${ }^{1}$ a las propuestas de corte más administrativistas y que no cuestionan ni alteran la estructura fundamental de un sistema de gobierno sino que más bien persiguen profundizar y perfeccionar al mismo, esta profundización y perfeccionamiento puede ser de carácter fiscal, político o administrativo ${ }^{2}$. Es así como los intentos descentralizadores $^{3}$, o más bien las reacciones al excesi- vo centralismo Chileno en este artículo se identifican a través de seis acontecimientos históricos: 1) El intento federalista de Infante de 1826; 2) El intento federalista de León Gallo de 1859; 3) El frustrado parlamentarismo Chileno de 1891-1925; 4) La primera regionalización de 1939 a 1970; 5) La regionalización de Pinochet de 1973 a 1989 y finalmente; 6) Las reformas político-administrativas de la concertación de partidos por la democracia en la década de los $90^{4}$.

A partir del análisis de estos intentos descentralizadores el objetivo que persigue este trabajo es explicar el actual carácter administrativo que adopta la des-

1 Por ejemplo, pasar de un estado unitario a uno federal o de un sistema presidencial a uno parlamentario.

2 En este artículo, se entiende por descentralización aquel proceso de transferencia de poder políti$\mathrm{co}$, fiscal y administrativo desde el nivel central a los niveles subnacionales del gobierno. Cuando el proceso se concentra más en la transferencia de funciones administrativas de un nivel de gobierno a otro sin pérdida total o parcial de la autoridad o del patrimonio, se le llama desconcentración de funciones o descentralización administrativa. Cuando el proceso se concentra más en aspectos de autonomía política o pérdida total o parcial del poder político por parte del gobierno central, al proceso se le llama descentralización política. Básicamente esta es la distinción que se hace en este artículo. Cabe señalar que el objetivo fundamental de este manuscrito no es discutir las distintas acepciones y significados que existen en torno a la descentralización.

3 En este artículo se denomina "intento descentralizador" a aquellos acontecimientos político-administrativos que demandaban al Estado central una mayor distribución territorial del poder político, administrativo y fiscal.

$4 \quad$ La concertación de partidos por la democracia es la coalición política de centro izquierda que ha gobernado el ejecutivo desde 1990 a la fecha. La coalición política de centro derecha se denomina alianza por chile. 
centralización situando su origen a partir de 1925. A partir de esa fecha los intentos descentralizadores se pueden observar formando parte de una estrategia que utiliza el Estado Chileno para fortalecer el proceso de modernización administrativa y de desarrollo económico del país.

El principal resultado que arroja el análisis de los acontecimientos históricos es que se distinguen claramente los intentos descentralizadores que provienen desde las regiones y que persiguen la distribución del poder político, de los intentos descentralizadores que provienen desde el propio centro nacional y que tienen como prioridad la desconcentración de funciones o descentralización administrativa. Los primeros intentos descentralizadores son los de tipo político y provienen de movimientos regionalistas o federalistas y comprende el período de 1810 (comienzo de la independencia chilena) hasta 1925. En este tipo de reacciones se encuentran los intentos federalistas de 1826,1859 y el frustrado período parlamentarista de 1891 a 1925.

Los segundos intentos descentralizadores son los de tipo administrativo con vocación desarrollista y se pueden observar e identificar aproximadamente a partir del año 1925 hasta la fecha. A diferencia de los primeros, éstos tienen un carácter vertical y surgen desde el propio centro político nacional desde donde se despliegan hacia todo el territorio nacional. Estos intentos se pueden ver reflejados específicamente a partir del año 1939 con la creación de la corporación de fomento y en 1965 con la creación de la oficina de planificación nacional, modelo reformado pero consolidado por Pinochet desde 1973 a 1989. En una etapa de construc- ción se encuentran los intentos descentralizadores pos Pinochet en los 90. No obstante, estos se caracterizan por ser el producto de arreglos institucionales más administrativos que políticos caracterizándose como un proceso más desconcentrador de funciones en donde aún prevalece un factor vertical, centralista y administrativo.

Para dar cuenta del objetivo, el artículo se estructura en dos grandes apartados. La primera parte titulada "Los intentos descentralizadores desde 1810 a 1925" da cuenta del estilo político adoptado por la descentralización asociada a movimientos federalistas y parlamentaristas en aquel período. La segunda parte titulada "Los intentos descentralizadores desde 1925 a la Concertación" da cuenta del estilo administrativo que a partir de esa fecha adoptó la descentralización asociada a una estrategia de desarrollo económico y de modernización administrativa impulsada por el propio Estado.

\section{Los intentos descentralizadores desde 1810 a 1825 . El centralismo en los primeros arreglos constitucionales en Chile}

Los sucesos que provocaron la emancipación política de América Latina en su conjunto constituyen parte de un proceso histórico que transcurre entre 1808 y 1824 (Silva, 1995). Sin pretender sostener que la emancipación puede ser explicada exhaustivamente por estos motivos, se podría señalar que este proceso se erigió como una lucha de reivindicaciones ante los siguientes aspectos: la deficiente administración colonial, el régimen comercial de monopolio, la poster- 
gación de criollos, el absolutismo y la tiranía de la autoridad virreinal tanto del modelo Borbónico como Hasburgo (Rojas, 2004). También en aquel período existió una fuerte influencia de la filosofía de la ilustración producto del influjo que ejercieron en los criollos ilustrados los políticos europeos, la influencia de la revolución francesa, el ejemplo de la independencia de los Estados Unidos de Norteamérica, la invasión de Napoleón en España y la reacción que provocó en América el absolutismo de Fernando VII luego de su restauración en 1814 y del desconocimiento que hizo éste de la constitución de Cádiz (Halperin Donghi, 1986).

A partir de 1810 en Chile se desarrolló un proceso similar al ocurrido en otras colonias españolas que rompieron sus vínculos políticos con la metrópoli. El dieciocho de septiembre de ese año el cabildo de la ciudad de Santiago delegó sus poderes en un grupo de siete personas que conformaron la primera junta de gobierno (Collier y Sater, 1998). Este acto fue el inicio de un proceso que culminaría con la independencia Chilena de España, después de más de dieciséis años en los que se mantuvo un estado de guerra intermitente con las tropas españolas enviadas desde Perú.

En 1814 ante el riesgo del regreso del régimen español, se eligió establecer un código político titulado reglamento para el gobierno provisorio, sancionado el diecisiete de marzo de 1814 que concentró amplias facultades en el ejecutivo. Así se redactó este reglamento constitucional que centralizó el poder político en un director supremo y que en su artículo primero señalaba lo siguiente: "las críticas circunstancias del día obligaron a concentrar el poder ejecutivo en un individuo" (Junta de Constituciones: 1814). El motivo de esta centralización del poder fue el peligro inminente de la guerra, lo cual hacía indispensable concentrar en una persona el poder ejecutivo. Este reglamento constó de trece artículos y contempló un senado consultivo integrado por siete miembros elegidos por el director supremo (Junta de Constituciones: 1814).

A su vez, el proyecto de constitución provisoria para el Estado de Chile de 1818 sancionado el diez de agosto de ese mismo año, fue dictado mientras gobernaba Bernardo O'Higgins. Esta constitución estableció la separación de poderes del estado y al mismo tiempo estableció que el poder ejecutivo quedara a cargo del director supremo al cual le otorgaba amplias atribuciones. Estableció al menos tres poderes del estado: director supremo, senado y poder judicial y reconoció las provincias existentes a la fecha, Santiago, Concepción y Coquimbo (Comisión Constituyente, 1818). Como resultado de la intensa lucha por conseguir independizarse totalmente de la corona española, O'Higgins, que en 1818 había sido nombrado director supremo de Chile, gobernó el país con poderes autoritarios y centralistas hasta 1823 cuando la hostilidad popular contra su régimen le obligó a dimitir (Villalobos, 1987:103). Esta carta constitucional provisoria recogió un caudal cuantioso de la herencia española colonial, ya que aceptó la necesidad de un ejecutivo centralizado y fuerte, pero sometido a un control acucioso desde un órgano colegiado, que para este caso sería el senado.

Por su parte, en la constitución de 1822 se estableció un congreso bicame- 
ral donde el poder legislativo contaba con facultades fiscalizadoras, consultivas y jurisdiccionales (Convención Nacional Constituyente, 1822). En esta época se decidió cambiar la organización provisional del país por otra más estable pero no menos centralizada. Era necesario que la república entrase a establecer sus instituciones liberales. Esta constitución fue promulgada el treinta de octubre de 1822. El gobierno organizado sobre la base del régimen representativo quedaba dividido en tres poderes independientes: ejecutivo, legislativo y judicial. El poder ejecutivo estaba a cargo del director supremo, elegido por el congreso por una mayoría de dos tercios de sus miembros, duraba seis años en el mando y tenía la posibilidad de ser reelegido por cuatro años más. Se le dotaba de la potestad reglamentaria y del ejercicio de la soberanía externa (Convención Nacional Constituyente, 1822).

La constitución de 1823 conocida como la constitución moralista ${ }^{5}$ (Silva, 1995:152) tuvo como antecedente el acta de unión y el reconocimiento de las tres provincias existentes a la fecha. Esta constitución fue firmada por los representantes de estas tres provincias: Santiago, Coquimbo y Concepción. Además se dedicó el título XIX a las municipalidades las cuales quedaban supeditadas a las ordenes de los consejos departamentales quienes a su vez eran representantes y designados por el poder ejecutivo. Las disposiciones de esta constitución se refieren a diferentes aspectos de la organización y carácter del estado, por ejemplo que el Estado de Chile se declaraba unitario y la soberanía reside en la nación (Congreso Nacional Constituyente, 1823).

Fue hasta 1826 cuando se dictaron las llamadas leyes federales las que fueron redactadas por José Miguel Infante. Mediante estas leyes se trató de aplicar en Chile el sistema federal de Estados Unidos. Dentro del conjunto de leyes federales que dan inicio legislativo al proyecto federalista se creó el cargo de presidente de la república el que se entregó a un militar, el teniente general Manuel Blanco Encalada (Silva, 1995).

\section{Primer acontecimiento descentralizador: el intento federalista de Infante de 1826}

El cuatro de julio de 1826 el congreso adoptó el federalismo y dispuso que se redactara una nueva constitución. A pesar de la resolución del congreso, este proyecto federal de 1826 no alcanzó a consolidarse en la constitución (Donoso, 1963: 37). Fue impulsada por el federal y admirador de la política estadounidense José Miguel Infante Rojas y lo más destacado de este ensayo fue la división del territorio en ocho provincias (Coquimbo, Aconcagua, Santiago, Colchagua, Maule, Concepción, Valdivia y Chiloé). Además proponía que todos los cargos, incluidos gobernadores y curas párrocos, serían sometidos a votación popular6. Este intento constitucional fue

5 Se le llamó moralista porque esta constitución tenía un capítulo especial relativo a la moralidad, en el titulo XXII del artículo 249 al 261 se trataba de regular la vida de las personas.

El voto para aquella época era censitario y no universal. 
imposible llevarlo a la práctica, entre otros motivos, por la falta de recursos económicos y de comunicación interterritorial, así como por la inexistencia de información y cultura cívica para aplicar un modelo estadounidense en una realidad tan alejada de ella.

El federalismo dado a conocer principalmente por la delegación diplomática de Estados Unidos que llegó a Chile en 1824 , luego de que el país del norte reconociera la independencia de los países de la naciente América Latina, respondía fundamentalmente a los deseos de autonomía de la provincias de Concepción y Coquimbo, en oposición al ya excesivo centralismo ejercido por Santiago para ese tiempo (Frías Valenzuela, 1960).

El mandato de Manuel Blanco Encalada que se había iniciado el nueve de julio de 1826 sólo duró hasta septiembre de ese mismo año cuando renunció debido a los desacuerdos que tuvo con el congreso para resolver la crisis que afectaba al país. Su sucesor, Eyzaguirre no tuvo mejor suerte. Era muy difícil gobernar sin fondos para pagar los sueldos de los nuevos empleados públicos electos en provincias y un ejército que además se amotinaba continuamente. Tampoco el nuevo gobierno contaba con los medios legales para ejercer su autoridad debido a que el federalismo había desarticulado la administración y al gobierno central y el congreso se arrogaba la hegemonía total. A lo anterior, se sumaba el clima de inseguridad y agitación provocado por las elecciones populares que se realizaban en las ocho nuevas provincias del país (Silva, 1995:156-157).

En este contexto de inseguridad y agitación social se produce el golpe de estado el veinticinco de enero de 1827 , encabezado por el general federalista Enrique Campino apoyado por los federalistas extremistas se dirigieron a Santiago y entraron al congreso y apresaron a los diputados más conservadores también llamados pelucones, no obstante, este levantamiento fue controlado. Después de ello el congreso nombró presidente a Ramón Freire el cual dejó el cargo al aprobarse una ley que exigía el acuerdo del congreso para designar a ministros de Estado, hecho ocurrido en 1827. Asumió el cargo el presidente Pinto quien decidió disolver el congreso y suspender la aplicación de las leyes federales y llamó a elecciones para otra asamblea constituyente que se llevaría a efecto en enero de 1828 (Silva, 1995:158).

Posterior a este intento federalista para descentralizar el Estado, deviene la constitución de 1828 promulgada por el gobierno de Francisco Antonio Pinto. Esta constitución de corte liberal se inspiró en la revolución francesa, en la constitución emanada en 1812 en las cortes de Cádiz y en el ensayo federal chileno de 1826 (Silva, 1995). En ella aparecen precisados el concepto de nación, territorio y la división del país en ocho provincias. En esta constitución se observa un notable esfuerzo por descentralizar al país lo cual se refleja en su introducción donde se señala que "las provincias no fluctuarán en lo sucesivo entre turbulencias peligrosas y una dependencia ilimitada del gobierno" (Asamblea Constituyente, 1828).

Esto provocó que se reconocieran diversas atribuciones a las provincias y a las municipalidades, por ejemplo, se estableció que el gobierno y la administración interior de las provincias se ejerciera 
en cada una por una asamblea provincial y por un intendente. La asamblea provincial estaba compuesta por miembros electos por el pueblo mientras que el intendente debía ser designado por el poder ejecutivo. Por su parte, se estableció en el artículo 118 de la constitución que en cada villa o ciudad donde exista un municipalidad habrá un gobernador local cuyo nombramiento se hará a pluralidad absoluta de sufragios hechos en la municipalidad (Asamblea Constituyente, 1828). No obstante, a pesar de la notable disposición explícita expresada en esta constitución para descentralizar al Estado, esta carta constitucional no tuvo el impacto político esperado, como consecuencia, se produce una recuperación del centralismo perdido en el intento federalista el cual se consolida con la carta constitucional de 1833.

\section{Recuperando el centralismo perdido: Diego Portales y la construcción de un gobierno fuerte y centralizado}

La constitución de 1833 fue promulgada el veinticinco de mayo de ese año bajo el poder de José Joaquín Prieto y rigió a Chile hasta 1925 . Fue redactada por una comisión integrada por Mariano Egaña y Manuel José Gandarillas y su inspiración y contenido representaba el pensamiento político de Diego Portales (Villalobos, 1987). En cuanto al contenido doctrinario, la constitución de 1833 encerraba las bases fundamentales de nuestro régimen institucional: soberanía na- cional, régimen representativo, división de los poderes públicos, responsabilidad gubernamental y garantías individuales (Gran Convención de Chile, 1833).

Se estableció un gobierno fuerte y centralizado, señalando que la soberanía reside en la nación y ésta delega poder en autoridades que establece la propia constitución. El poder legislativo fue bicameral y el poder ejecutivo quedó en manos del presidente de la república, el cual gozaba de un amplio poder, duraba cinco años en el cargo y podía ser reelegido para el período siguiente (Villalobos, 1987). Así se pueden observar algunos rasgos constitucionales de orden presidencialista, como por ejemplo, que la constitución fue la que logró estabilizar políticamente a Chile durante casi cien años, pero con un sello absolutamente presidencial y centralista con voto censitario y representativo. De este modo, se comenzó a configurar la organización y formación del estado republicano con una constitución que garantizara, reitero, un gobierno fuerte, centralizado y basado principalmente en la figura del presidente de la república ${ }^{7}$.

Uno de los aspectos que se derogaron con esta nueva constitución fue la posibilidad de que las provincias estuvieran conformadas por una asamblea provincial cuyos integrantes sean electos popularmente, en su reemplazo se estableció lo siguiente: "que el gobierno superior de cada provincia en todos los ramos de la administración, residirá en un intendente quien lo ejercerá con arreglo a las leyes y a 
las órdenes e instrucciones del presidente de la república, de quien es agente natural e inmediato" (Gran Convención de Chile, 1833).

\section{Segundo acontecimiento descentralizador: el intento federalista de Pedro León Gallo en 1859}

A comienzos del año 1850 y transcurridos casi veinte años de dominio del conservadurismo portaliano, las nuevas generaciones políticas empezaban a preparar el fin de esta época política. Las primeras manifestaciones se dieron en la prensa que crecientemente expresaba el anhelo de los postulados liberales. Con la creación del club de la reforma y la sociedad de la igualdad ${ }^{8}$ estas ideas iniciaron su realización, las que en algunos casos se concretaron a través de revueltas como las posteriores intentonas revolu- cionarias y regionalistas de 1851 y 1859 (Frías Valenzuela, 1960).

El gobierno de Manuel Montt de 1851 a 1861 comenzó con una oposición muy activa que cuestionaba, entre otras cosas, el autoritarismo y el centralismo de la capital nacional Santiago que se había consolidado a partir de 1833, estallando movimientos de resistencia en 1851 en Concepción y La Serena. En Concepción ciudad ubicada al sur de Chile el conflicto de $1851^{9}$ se resolvió cerca del río Loncomilla (Frías Valenzuela, 1960:452). En ese mismo año en La Serena (norte de Chile) la revolución fue vencida ${ }^{10}$.

Frente a esta crisis revolucionaria impulsada por las regiones que reclamaban mayor autonomía y más descentralización el presidente Montt y su ministro del interior Antonio Varas, resolvieron perdonar a la mayor parte de los exaltados (Frías Valenzuela, 1960:454) y consiguieron que el congreso le otorgara al

Organizada en 1850 la Sociedad de la Igualdad planteaba la necesidad de una transformación revolucionaria de la sociedad que daría inicio a una nación de hombres libres e iguales. Inspirada en los ideales de la revolución francesa, fue la primera vez que los intelectuales radicales establecieron alianzas con sectores populares. Por su parte El club de la Reforma tenía como objetivo difundir por medio de la prensa y de la palabra las ideas democráticas, apoyar las ideas liberales y difundirlas a las masas (Pinto, 1965). Este Club representa un incipiente movimiento sociopolítico que generaría repercusiones en el futuro cambio de gobierno en Chile.

9 En la ciudad de Concepción se enfrentaron las fuerzas del general José María de la Cruz y las fuerzas del gobierno dirigidas por el ex presidente Bulnes. De la Cruz fue derrotado el ocho de diciembre de 1851 por las fuerzas del gobierno central. El catorce de diciembre se rindió en $\mathrm{Pu}-$ rapel con lo cual concluyó la revolución del sur (Frías Valenzuela, 1960) y también el intento por descentralizar el poder del Estado Nacional. Es necesario aclarar que este conflicto no se debe únicamente al excesivo centralismo del Estado Chileno sino que también estaba motivado además por un espíritu regionalista, aristocrático y militar de la zona, donde la familia del General Cruz tenía poderosas vinculaciones (Frías Valenzuela, 1960:452).

10 En la Serena los revolucionarios fueron dirigidos por José Miguel Carrera Fontecilla -hijo del caudillo de la Independencia- y atacados por Juan Vidaurre y Victorino Garrido representantes y defensores del statu quo en la época. Al enterarse de lo sucedido con Cruz en el sur, los insurrectos abandonaron la ciudad. 
presidente mayores facultades extraordinarias por catorce meses para resolver cualquier situación que se pudiera presentar. Entre las medidas estratégicas de índole territorial se inició la colonización en el sur del país ${ }^{11}$ (Frías Valenzuela, 1960).

No obstante, quizás dentro de los levantamientos regionalistas y federalistas más influyentes de la historia nacional está la llamada revolución constituyente impulsada en 1859 por Pedro León Gallo $^{12}$ (Donoso, 1963: 62). Estando en Copiapó, ciudad ubicada al norte de Chile, se percató de lo retrogrado del centralismo y se convirtió en un liberal y en un apasionado regionalista, el cual, con su propio dinero organizó a más de mil hombres para iniciar su revolución constitu- yente en contra del centralismo de la capital nacional Santiago (Silva, 1995).

León Gallo logró quedar al frente del club constituyente ${ }^{13}$ que proponía el impulso de reformas constitucionales que tendían a la descentralización y al federalismo. Producto de sus estudios y de las ideas liberales de la época había llegado a la convicción de que la educación debía laicizarse, como también debía existir una mayor libertad electoral. Esta sumatoria de antecedentes lo puso de frente a las aspiraciones del presidente Montt, con lo cual comienza la lucha entre el centralismo chileno y la idea liberal y federalista de León Gallo (Silva, 1995). Los constituyentes comenzaron a pensar en un nuevo orden político institucional, una nación federal, hecho que estimaban era lo mejor para el desarrollo de la república Chilena ${ }^{14}$.

11 En este proceso se colonizó Llanquihue y Vicente Pérez Rosales recorrió la zona y fundó la coIonia de Melipulli, actual Puerto Montt. Posteriormente, otros colonos alemanes se instalaron en Osorno, Puerto Octay, Puerto Varas, Frutillar, La Unión y Río Bueno. Entre 1851 y 1860 llegaron más de tres mil alemanes y colonizaron Valdivia y Llanquihue.

12 Pedro León Gallo adinerado aristócrata nació el doce de febrero de 1830, sus padres fueron Miguel Gallo Vergara, empresario minero y su madre fue una mujer que para aquella época era denominada "progresista", Candelaria Goyenechea y de la Sierra.

13 El club constituyente postulaba la reforma de la constitución de 1833. Este club postulaba la idea que los cambios sociales debían provenir de una base social más amplia y heterogénea. De esta manera iba tomando cuerpo un pensamiento de desmantelar el orden autoritario y centralizador de Diego Portales plasmado en la constitución de 1833, a la cual se le juzgaba como el origen fundamental de todas las desgracias que afligían entonces a la república (Donoso, 1963:62).

14 De esta manera el ejército revolucionario de Copiapó avanzó hacia el sur para enfrentarse a las tropas del ejército de Montt. Copiapó, donde residía León Gallo, fue la ciudad más resistente ya que las demás entre las que destacaba San Felipe, Talca y Concepción, fueron sofocadas rápidamente (Frías Valenzuela, 1960). El avance de las tropas federalistas continuaba y avanzaban hasta Vallenar, ciudad que tomaron sin ninguna resistencia, desde ahí se dirigieron a La Serena. Fue en las cercanías de esta ciudad donde se desarrolló la batalla de Los Loros el 14 de marzo de 1859, donde los constituyentes federalistas finalmente pusieron en fuga al ejército de Montt, de esta manera las tropas de León Gallo vencieron y tomaron la ciudad (Silva, 1995:179). Este hecho provocó un hondo impacto en el país, los liberales capitalinos ya se imaginaban entrando triunfante al palacio de gobierno al caudillo copiapino. De esta forma, los liberales capitalinos ya no sólo se habían desembarcado de la revuelta constituyente, sino que ahora criticaban el accionar de León Gallo y sus hombres. De esta forma la revolución adquirió un 
Una vez vencida la revolución constituyente federalista de 1859 se comenzaron a proponer una serie de reformas a la constitución centralista de 1833 (Donoso, 1963) y se producía el hito fundacional de la nueva etapa de la historia, la llamada etapa o república liberal (Frías Valenzuela, 1960).

\section{De los intentos federalistas a los intentos parlamentaristas}

La llamada etapa o republica liberal que también se conoce como expansión nacional es el período histórico que sucede entre 1861 y la muerte de José Manuel Balmaceda en $1891^{15}$ (Villalobos, 1987). Durante esta etapa se producen una serie de reformas constitucionales, se dicta el código penal, la ley de atribuciones de los tribunales, se pone fin al fuero eclesiástico y como una forma de disminuir el centralismo -que a estas alturas se vestía con ropajes de excesivo ejecutivismo o presidencialismo- se disminuyeron algunas atribuciones al ejecutivo en beneficio del legislativo, aún cuando este periodo se sustentó sobre las mismas bases espirituales y políticas de la etapa anterior (ViIlalobos, 1987:471). Estas doctrinas liberales y específicamente los grupos políticos liberales comenzaron un proceso de laicización del estado, que para aquella época tenía como religión oficial solamente a la católica ${ }^{16}$ (Gran Convención de Chile, 1833).

Muy lentamente, se empezó a desmontar el marco constitucional y legal que limitaba el avance de los liberales. Una nueva ley electoral en 1869, la prohibición de la reelección del presidente de la república, las reformas constitucionales de los años 1873-74, y la promulgación de la ley de la comuna autónoma en 1890 fueron distintos pasos que se orientaban en un mismo sentido: liberalizar las instituciones políticas y descentralizar el poder político del Estado.

La política era ahora el escenario para un debate público sobre al menos dos cuestiones importantes. Por un lado la discusión se centró en avanzar en la laicización de la sociedad o mantener la tutela clerical en los asuntos de la educa-

sesgo solamente atacameño y/o copiapino y las tropas de León Gallo fueron detenidas entre Serena y Coquimbo. Finalmente, Pedro León Gallo es derrotado en el combate de Cerro Grande, y desde allí salió exiliado a Argentina, Estados Unidos y Europa, con la cual la revolución constituyente federalista queda vencida (Frías Valenzuela, 1960:470).

15 Dentro de las principales características de esta etapa de la historia chilena podemos distinguir las siguientes: el signo de los gobiernos deja de ser conservador y vendría un gobierno de transición para luego pasar los liberales a ser prácticamente los dueños del poder político. Otro de los rasgos característicos del período, es que el país se extiende tanto al norte como al sur. Al norte producto de la guerra del pacífico 1879-1881 y se anexan las provincias de Tarapacá (hasta entonces peruana) y Antofagasta (hasta entonces boliviana). Se anexa definitivamente la zona de la Araucanía, proceso que se inicia con Cornelio Saavedra en 1857 y comienza a consolidarse con la fundación de Temuco el año 1884 (Villalobos, 1987).

16 Estas luchas teológicas comienzan con la modificación de 1865 a la constitución de 1833, donde era posible la aceptación de otros cultos en forma privada. 
ción, la moral y las relaciones con el estado. Y por otra parte, la discusión sobre el centralismo y la excesiva concentración del poder pasó de las propuestas -o mas bien intentos- federalistas a una disputa entre las atribuciones del poder legislativo y el poder ejecutivo, cuestión que se reflejó en constantes acusaciones ministeriales que derivaban en una excesiva rotativa ministerial. Finalmente esta discusión también terminó por zanjarse mediante la vía violenta en 1891.

\section{La época parlamentaria en Chile ¿el tercer intento descentralizador?}

Dentro de los vaivenes Chilenos producidos por la tensión centralismo / descentralización y/o la concentración del poder en uno de los poderes del estado -en este caso en el ejecutivo- en 1891 estalló la guerra civil entre opositores al presidente Balmaceda -parlamentaristas- $y$ los defensores del statu quo -presidencialistas- (Villalobos, 1987). Con el término de la guerra civil en 1891, de la cual resultó derrotado el presidente José Manuel Balmaceda, se podría pensar -de manera muy ingenua- que se alcanzó una recuperación de la pérdida parcial del poder político que hasta la fecha había estado centralizado. No obstante, el poder que se recuperó fue el que había perdido sólo un sector del país: la oligarquía de plutócratas y de aristócratas que con el tiempo transformaron al parlamentarismo en una política de círculos oligárquicos santiaguinos a los cuales seguían las provincias y la mayoría de la clase media, ante la total indiferencia del pueblo (Frías Valenzuela, 1960:571).
Este sistema de gobierno que se conoció como parlamentarismo no modificó la constitución presidencial de 1833, es decir, el país siguió funcionando bajo un presidencialismo constitucional. De igual forma el poder quedó radicado fundamentalmente en el parlamento y por consiguiente en los partidos políticos más influyentes. Este período se caracterizó por una constante rotativa ministerial como resultado de la imposibilidad de los partidos por lograr mayorías estables en el congreso, a esta época también podría llamársela la época de un notable y desordenado gobierno dividido en Chile. A esto se sumó la disposición de que tanto diputados como senadores podían ser ministros de manera simultánea a su cargo parlamentario. Esto trajo como consecuencia que los gobiernos prácticamente se paralizaran y no se lograba alcanzar las decisiones ni soluciones necesarias a los graves problemas sociales existentes en la época que tenían su origen en las transformaciones y el auge económico que se encontraba viviendo el país ${ }^{17}$ (Frías Valenzuela, 1960).

Con respecto a la descentralización del Estado durante este período, uno de los avances más sustantivos en materia de ley fue la promulgación de la ley de comuna autónoma aprobada el veintidós de diciembre de 1891, la cual se basó en la ley de 1854 pero se diferenció de ella en que esta última definió con claridad las fuentes de recursos para solventar las inversiones y gastos municipales y aseguró la autonomía de las comunas mediante la eliminación del rol municipal de intendentes, gobernadores y subdelegados $y$, en particular, mediante el establecimiento 
de las asambleas de electores (Salazar y Pinto, 1999:280).

Los aspectos más destacados de la ley de comuna autónoma fueron los referidos a las asambleas de electores a las que se le concedió poder para votar los presupuestos y deliberar sobre los gastos posteriores que proponía el municipio. No obstante, rápidamente cuando las comunidades locales y algunos sectores populares comenzaron a aprovechar la oportunidad que otorgaba la ley y los artículos más participativos, los congresistas modificaron la ley de comuna autónoma para eliminar las democráticas asambleas de electores y repusieron las oligárquicas asambleas o comités de mayores contribuyentes ${ }^{18}$ (Salazar y Pinto, 1999: 281).

Luego de este fracaso parlamentarista en 1925 el presidente Arturo Alessandri Palma determinó una comisión consultiva para elaborar la nueva constitución presidencialista. Entre los aspectos fundamentales de la constitución de 1925 destacó la separación definitiva en- tre la Iglesia y el Estado y la imposibilidad de disolver el congreso por parte del presidente de la república. Esta constitución fijó un régimen representativo, de carácter presidencial y con una separación estricta de poderes. El presidente desarrollaría las funciones de jefe de estado y gobierno, nombrando y removiendo a los ministros. Existiría un congreso bicameral que tendría una función colegiadora, la forma de gobierno territorial sería unitaria y se estableció una cierta posibilidad de descentralización administrativa (Ministerio del Interior, 1925).

\section{1925 y el regreso del presidencialismo, la despedida del federalismo y el parlamentarismo como alternativas al centralismo chileno}

El pronunciamiento militar del cinco de septiembre de 1924 sería el hito que marcaría el término del parlamentarismo en Chile. La junta militar que asumió provisionalmente el gobierno derogó por de-

17 En este período también emergieron las primeras organizaciones obreras, tales como las mancomunales, las sociedades de resistencia y los sindicatos, que surgieron al calor de la lucha social. Asimismo, se formaron los primeros partidos políticos obreros (Salazar y Pinto, 1999). Si antes el problema era el excesivo centralismo que impedía a las provincias influir en las decisiones nacionales, en el periodo "parlamentario" fue la insensibilidad de los gobernantes y definitivamente su incapacidad administrativa para enfrentar el conjunto de conflictos que afectaba a la sociedad chilena: movilizaciones obreras y mineras, efervescencia estudiantil, malas condiciones de vida de los obreros, alcoholismo y falta de educación.

18 Además de esto, en esta época, la vieja aristocracia austera y rural anterior al periodo parlamentario fue reemplazada por una oligarquía amante del lujo, la moda y las grandes fiestas. Expresión de esto fue la construcción de palacios y mansiones de estilo europeo en el centro de Santiago. Chile se comenzó a transformar en un país de contrastes, donde la elite política y social estaba constituida por un sector muy reducido. La crítica impactó profundamente, sobre todo, porque junto con el término del siglo XIX en Chile se había iniciado un período de bonanza económica que se concentraba en unos pocos y que duraría hasta fines de la década del 20 del siglo pasado (Frías Valenzuela, 1960). 
creto de ley número trece, entre otras cosas, la ley orgánica de municipalidades existente hasta esa fecha y disolvió todos los municipios de relevancia del país, designando en su lugar a intendentes y regidores, los cuales debían ser designados por decreto ministerial (Salazar y Pinto, 1999:290). La centralización que comenzaba respondía a una doctrina que partía del supuesto de que el éxito de una comuna y una municipalidad requería de un plan integral, en donde el objetivo era disciplinar a los municipios bajo un plan orgánico de desarrollo nacional que fue impulsado por el presidente lbáñez (Salazar y Pinto, 1999).

Por otra parte, a este período entre 1925 y 1973 también se le conoce como la etapa democrática presidencial. Es un período marcado por el ascenso de la clase media y los modelos políticos y económicos revolucionarios. Hay una gran prosperidad y un aumento sostenido del nivel de vida, mejoras en educación y salud y el país vive un proceso de industrialización. Después de algunos primeros años complicados en lo económico producto de la crisis mundial de 1929, en 1933 se fundan los grandes partidos populares, la democracia cristiana y el partido socialista de Chile.

En el año 1938 llega a la presidencia de la república la alianza política denominada frente popular cuyo líder era el político radical Pedro Aguirre Cerda, junto a él se instala un modelo económico estilo keynesiano de fuerte intervención estatal en el desarrollo económico nacional. Producto de esta inspiración desarrollista de la época, la descentralización adopta un nuevo ropaje y se convierte en una herramienta estratégica del propio estado para promover el crecimiento y desarrollo económico en el país. A partir de este supuesto, el veintinueve de abril de 1939 se funda la Corporación de Fomento (CORFO) y con ello el Estado se convierte en motor del dinamismo industrial y de crecimiento nacional.

\section{El cuarto intento descentralizador de 1925 a 1973: la era de la descentralización administrativa y la primera regionalización}

En el periodo de 1925 hasta 1973 podemos encontrar los antecesores más directos al actual ordenamiento territorial chileno. A este intento le podemos denominar primera regionalización. En esta época se produce un vuelco respecto a las características de los intentos por descentralizar al estado, los cuales hasta la fecha se habían caracterizado por ser demandas que provenían de fuertes movimientos regionalistas y federalistas que nacían en provincias y que en la mayoría de los casos tuvieron salidas violentas por la vía de la revolución o el levantamiento en armas.

A diferencia de lo anterior, para esta época ya casi desaparece de la agenda política la discusión sobre los intentos federalistas y/o parlamentaristas y se opta por un proceso de descentralización con un carácter administrativo que nace como estrategia desde el propio estado para que contribuya en ese entonces al proceso de modernización que iniciaba el Estado. De hecho, en la constitución de 1925 se dedica un artículo al tema de la descentralización del estado y se re- 
conoce en él que: "las leyes confiarán paulatinamente a los organismos provinciales o comunales las atribuciones y facultades administrativas que ejerzan en la actualidad otras autoridades con el fin de proceder a la descentralización del régimen administrativo interior" (Ministerio del Interior, 1928).

Con esta modalidad de descentralización se iniciará un proceso de descentralización administrativa pero basada en la consolidación territorial y con el claro objetivo de promover y fortalecer el crecimiento económico del país por medio del desarrollo regional (Boisier, 2000). Posteriormente, por medio de la regionalización se comenzaron a implementar algunos estudios y reformas impulsados por la corporación de fomento y la oficina de planificación nacional con el fin de promover mediante la regionalización y la descentralización un mayor crecimiento económico de las regiones ${ }^{19}$ (Boisier, 2001).

En 1950 la corporación de fomento como una forma de impulsar el desarrollo económico del país se propuso una nueva división política-administrativa que constaba de seis grandes regiones: Norte Grande, Norte Chico, Núcleo Central, Concepción y La Frontera, Región de Los Lagos y
Región de Los Canales. Esta división del territorio se basó principalmente en los aspectos geográficos y económicos. El objetivo de esta regionalización fue impulsar el desarrollo económico de cada región basándose en las características propias de cada zona: características geográficas, humanas y económicas (Boisier, 2001).

Por su parte, en 1965 la oficina de planificación nacional avanzó en la regionalización estableciendo nuevas regiones basadas en un sistema de polos de desarrollo económico. El territorio esta vez quedó dividido en once regiones y una zona metropolitana. Este sistema se caracterizó por la creación de unidades espaciales en las que cada una tuviera un lugar central determinado por una ciudad o polo de desarrollo económico que se expandiera al resto de la región. Se estableció la ciudad de Santiago y la zona metropolitana como principal centro del desarrollo nacional y tres polos de desarrollo multirregional que fueron Antofagasta, Valparaíso, Concepción y en un tercer nivel de jerarquía otra serie de polos de desarrollo regional $^{20}$ (Boisier, 2001).

En resumen, los procesos económicos que se comenzaron a suceder a partir de 1925 pero con mayor dinamismo

19 Sergio Boisier destaca la importancia que tuvieron en aquella época las catástrofes naturales como un elemento que detonó la adopción de políticas de desarrollo regional en Chile.

20 Las regiones y provincias quedaron constituidas como sigue: I región provincia de Tarapacá; II región provincia de Antofagasta; III región provincias de Atacama y Coquimbo; IV región provincias de Aconcagua y Valparaíso; V región provincias de O"Higgins y Colchagua; VI región provincias de Curicó, Talca, Linares y Maule; VII región provincias de Ñuble, Bío-Bío, Concepción, Arauco y Malleco; VIII región provincia de Cautín; IX región provincia de Valdivia y Osorno; X región provincias de Llanquihue, Chiloé y Aysén; XI región provincia de Magallanes; Zona Metropolitana. Este esquema de ordenamiento territorial es el que se constituye como argumento histórico para que actualmente Valdivia, Arica y Ñuble demanden autonomía regional en el país, ya que con la regionalización de Pinochet en 1973 estas ciudades perdieron su condición de cabeceras capitales de región. 
en los años cincuenta, llevaron a configurar en Chile una economía espacial que se asimilaba al modelo teórico centro-periferia, es decir, contar con un modelo de industrialización concentrado en un polo regional y en el abastecimiento de recursos desde los centros primarios ubicados en la periferia. Esto hizo que la vocación desarrollista del Chile de los años cuarenta, cincuenta y hasta finales de los sesenta entendiera la descentralización -enmarcada en un proceso de regionalización- como un proceso que permitiría generar un mayor dinamismo de la economía nacional y regional (Boisier, 2000).

Como consecuencia, a finales de los años sesenta la descentralización se instaló en el centro mismo de la cuestión regional y la política regional del gobierno de la época fue fundamentalmente una política de fomento al crecimiento económico regional. Se expresaba mediante la identificación clara de sus objetivos, así como del establecimiento de prioridades regionales a través de la definición de los polos de crecimiento como ubicaciones prioritarias para el desarrollo integrado urbano regional, delimitación de regiones y proposición de organismos regionales tanto de coordinación como de ejecución (Boisier, 2000).

\section{El quinto intento descentralizador. Pinochet y la segunda regionalización}

Con la llegada de la dictadura militar, de alguna manera se produjo un fenómeno que pudiese considerarse como paradojal, ya que la dictadura encabezada por Pinochet dio un fuerte impulso al proceso de regionalización y descentrali- zación iniciado en la década de los cincuenta. Para tal efecto, se promulgó el decreto número 212 del diecisiete de diciembre de 1973 que creó la Comisión Nacional para la Reforma Administrativa (CONARA) (Boisier, 2000). Esta comisión fue la que estableció la actual división político-administrativa nacional conformada por trece regiones y definió un sistema de administración con la finalidad de modernizar el Estado de Chile y desarrollar a las regiones del país.

Por las peculiares condiciones geográficas, Chile requirió una organización tal que permitiera un desarrollo descentralizado administrativa y regionalmente en función de los objetivos de integración, seguridad nacional, desarrollo socio-económico y la administración nacional. De esta manera, la regionalización y el sistema de descentralización administrativa que actualmente rige el país comenzó a aplicarse mediante los decretos ley 573 y 575 del año 1974 que persiguieron alcanzar la consolidación de esta nueva organización política, administrativa, social y financiera de las regiones (Boisier, 2000). Así el gobierno militar hizo suyo un discurso muy descentralizador pero para fortalecer su estrategia económica (Boisier, 2001).

Como se señaló anteriormente CONARA sería la encargada de poner en marcha la nueva regionalización para incrementar la integración nacional, desarrollar un sistema de seguridad nacional y alcanzar un desarrollo económico (Boisier, 2000). La integración nacional pretendía utilizar de mejor forma los recursos naturales para alcanzar una ocupación efectiva de todo el territorio nacional e integrar a la población en las regiones, de 
modo que exista una real igualdad de oportunidades dentro del proceso de desarrollo nacional. Desarrollar un sistema de seguridad nacional pretendía lograr la seguridad fronteriza y una cohesión interna para la ocupación humana de espacios vacíos del territorio. Alcanzar un desarrollo económico perseguía que los recursos existentes en el territorio debían ser utilizados con el objetivo de evitar la concentración del crecimiento económico que han alcanzado algunas ciudades del país (Boisier, 2000).

La división política administrativa de 1975 le otorgó una importancia crucial a las regiones en oposición a la importancia administrativa que tenían las provincias antes de $1973^{21}$. El objetivo de crear estas regiones era constituir una unidad que posibilitara la administración para el desarrollo a través de una real descentralización del sistema de toma de decisiones en los niveles locales. Por ello, las regiones debían contar con una dotación de recursos naturales que avale una perspectiva de desarrollo económico de amplia base, una estructura urbano rural que garantice un nivel de servicios mínimos a la población regional y contar con un lugar central que actúe como núcleo de la estructura económico espacial de la re- gión y oriente su dinámica de crecimiento (Boisier, 2000).

De este nuevo ordenamiento territorial de trece regiones entre las que se incluía a la región metropolitana, se esperaba que pudiera emerger finalmente una solución sustentable a la distribución de los recursos y a una administración política que respondiera a la necesidad de la gente en sus respectivos territorios. Era la solución ideal para seguir siendo un país unitario pero sin caer en federalismos utópicos y que procurase que el desarrollo económico se hiciese en verdadera armonía. No obstante, a más de treinta años de aquellas reformas la regionalización y la descentralización parecen ser un tema absolutamente pendiente (SUBDERE, 2000). Pero lo que más preocupa es que el centralismo se ha acentuado peligrosamente en el plano de la cultura, la identidad y la gestión local en Chile (Boisier, 2001).

\section{El intento descentralizador de la concertación}

Sería un tanto injusto dejar la sensación de que con la recuperación de la democracia en 1990 la concertación de partidos por la democracia (coalición política de centro izquierda en Chile) ha he-

21 Cabe destacar que desde los orígenes de la república hasta 1974 el país estuvo dividido desde el punto de vista político-administrativo principalmente en provincias. En 1811 existían solo tres provincias que con el transcurrir de los años y de acuerdo a la realidad territorial y a las necesidades administrativas se convirtieron en 25. Hoy día el territorio nacional se encuentra organizado en 13 regiones, 52 provincias y 345 comunas. Las actuales regiones son las siguientes: I Región de Tarapacá, II región de Antofagasta, III región de Atacama, IV región de Coquimbo, V región de Valparaíso, VI región del general libertador Bernardo O"Higgins, VII región del Maule, VIII región del Bío-Bío, IX región de la Araucanía, X Región de Los Lagos, XI región del General Carlos Ibáñez del campo, XII región de Magallanes y de la Antártica Chilena. 
cho un continuismo de los procesos de descentralización administrativa iniciados en 1950 y que no ha realizado mayores aportes sustantivos que no sean de carácter administrativo. En este aspecto cabe destacar dos importantes avances en materia de descentralización política tanto en los gobiernos regionales como en las municipalidades ${ }^{22}$ (Ministerio del Interior, 1992). Esto ha permitido que las municipalidades como organismos de la administración del Estado y los alcaldes y concejales como actores políticos se posicionen frente a la ciudadanía en su calidad de actores democráticos a partir de los años noventa (SUBDERE, 2000). El segundo de los avances ha sido la creación de los gobiernos regionales mediante la ley orgánica constitucional de gobierno y administración regional, la cual distingue claramente la función ejecutiva del intendente de la función administrativa del consejo regional (Ministerio del Interior, 1993). Esta ley se destaca en materia de desconcentración administrativa, ya que le dio vida administrativa y política a un organismo como las regiones que antes de 1990 tenían una escasa presencia en la vida ciudadana y sólo cumplían una función geopolítica de seguridad nacional. Hoy los gobiernos regionales deci- den más del $42 \%$ de la inversión nacional con carácter regional (Insunza, 2000).

De igual manera se puede apreciar que las instituciones subnacionales diseñadas a partir de 1992 aún mantienen una fuerte herencia centralista y un marcado acento administrativo. Por ejemplo, el hecho que aún hasta nuestros días la máxima autoridad política de los gobiernos regionales la constituya un intendente designado por el presidente de la república, representa una fuerte herencia borbónica y portaliana de carácter centralista. Borbónica en el sentido que para éstos el rey necesitaba burócratas leales tanto en los cabildos como en las intendencias para que los criollos no se levantaran en armas y menos aún exigieran autonomía (Rojas, 2004). Para Diego Portales, los intendentes eran agentes directos del presidente de la república que se debían ocupar de ejecutar las órdenes del gobierno central fortaleciendo con ello la idea portaliana matter, es decir, un gobierno fuerte y centralizado.

Aún con esta carga de herencia centralista, en los años noventa el concepto de descentralización administrativa $y$ en menor medida el de descentralización política se ha convertido en uno de los ejes sustentadores y potenciadores

22 En Chile actualmente existen tres niveles de gobiernos subnacionales: los gobiernos regionales, los gobiernos provinciales o gobernaciones y las municipalidades. En general la institucionalidad de las municipalidades está políticamente mejor establecida en tanto sus autoridades son elegidas mediante elección popular y universal. En tanto, en los gobiernos regionales para elegir a sus autoridades ejecutivas no se realizan elecciones populares. Los gobiernos regionales se componen de un intendente y un consejo regional; el intendente es designado por el poder ejecutivo, mientras que los integrantes del consejo regional son elegidos por los alcaldes y concejales entre candidatos propuestos por los partidos políticos. En las gobernaciones provinciales, el gobernador es designado por el Presidente de la República. 
del proceso de redemocratización y se encuentra en la base de la reforma del Estado Chileno. Lo que es innegable es que existen elementos constitucionales y culturales que determinan que la descentralización en la actualidad adquiera un carácter más administrativo -asociado a la desconcentración de funciones- que un carácter político asociado a la distribución del poder entre los organismos subnacionales. Por ejemplo, las leyes y la constitución definen la descentralización haciendo una clara distinción entre los conceptos de gobierno y administración del estado ${ }^{23}$ (SUBDERE, 2004). Ello condiciona notablemente el proceso puesto que establece que la facultad de gobernar sólo puede desconcentrase y únicamente la facultad de administrar puede descentralizarse.

Entre los factores culturales, el más importante lo constituye el predominio de una cultura centralista con resistencias al proceso descentralizador. Esta cultura se ha generado junto con un patrón inarmónico y desigual en el desarrollo del país, donde la región metropolitana históricamente ha presentado concentración en todos los ámbitos, en particular en la concentración económica y productiva (SUBDERE, 2000). Es por ello que tanto la ley orgánica de gobierno y administración regional como la ley orgánica constitucional de municipalidades, se muestran como fieles representantes de la tradición jurídico-política y de la cultura político-administrativa chilena, que no admite la descentralización del poder sólo admite la descentralización de la administración.

Al principio de los años noventa la descentralización tuvo un carácter político al democratizar la elección de alcaldes y concejales en las municipalidades. Con posterioridad ha tenido un sello de desconcentración y ha consistido principalmente en una transferencia de competencias desde la administración central a otras administraciones como es el caso de los gobiernos regionales y municipalidades. Esta desconcentración también se ha caracterizado por transferir atribuciones del ejecutivo a autoridades jerárquicamente inferiores con el objeto de administrar ciertas materias, claro está que estos organismos subnacionales no poseen facultades resolutivas y siempre se encuentran subordinadas al poder central.

\section{Conclusiones}

La descentralización administrativa y el centralismo chileno claramente tienen sus orígenes en los arreglos institucionales y constitucionales de la nación. En este centralismo se pueden distinguir

23 Sergio Boisier (2000) clarifica de mejor forma este punto en su artículo "la vocación regionalista del gobierno militar" al citar parte del discurso del presidente de la república Patricio Aylwin con motivo de la promulgación de la ley orgánica de gobierno y administración regional 19.175 en 1993... "...el gobierno regional sigue residiendo en el Intendente, puesto que Chile es un estado unitario, pero la administración de la región se ejerce por el Intendente en conjunto con el Consejo Regional". "Hay que observar cuidadosamente la fina distinción que el presidente—un experto en la materia-hacía entre gobierno y administración, el primero no sujeto de descentralización, sólo de desconcentración, en tanto que la segunda sí descentralizada". 
diversos intentos descentralizadores, no obstante, se pueden identificar dos estilos diferenciados.

Existe un estilo de descentralización que podemos denominar endógeno o de abajo hacia arriba. Este estilo tiene un fuerte componente político y se basó en intentos revolucionarios que implicaban un cambio radical en el modelo de gobierno y ordenamiento constitucional. Estos intentos que en algunos casos se concretaron, fueron los que estaban por federalizar al país en 1826, 1851, 1859 y los que estaban por pasar de un sistema presidencial altamente centralizado a un sistema parlamentario que duró treinta y cuatro años de 1891 a 1925. Ambos intentos de cambios institucionales radicales no dieron ni resultados políticos ni se plasmaron en la vida social y política chilena. Por el contrario, se convirtieron en motivos suficientes para reaccionar y volver a centralizar el poder tanto en 1833 como en 1925 a través de diseños institucionales que aseguraran la estabilidad política interna de la nación. Frente a estos intentos de cambios radicales se impuso y consolidó un sistema institucional presidencial, unitario y centralizado de gobierno. Es así como a partir de 1925 se opta, pero ahora desde el propio estado, por una clara política de descentralización de carácter administrativa que contribuya al proceso de modernización y crecimiento económico que el país se preparaba a enfrentar.

De lo anterior se desprende el segundo estilo de intentos descentralizadores los cuales podemos denominar verticales o de arriba hacia abajo y con un carácter más administrativo, estos intentos los podemos observar desde 1925 a la fecha. En este estilo de descentralización se consolidan instituciones y organizaciones de gobierno que tienen como principal objetivo fortalecer el desarrollo económico de las regiones y modernizar al estado, para ello se descentralizan funciones administrativas a los niveles inferiores de gobierno.

Finalmente, se puede decir que en la actualidad la descentralización administrativa se encuentra en una etapa de consolidación a través de las nuevas reglas del juego creadas a partir de 1992, las cuales responden a un diseño institucional iniciado en 1925 que persigue la modernización del estado y el crecimiento económico del país.

Como consecuencia no se observan instituciones ni movimientos regionalistas sustantivos que pudieran llevar a pensar en un estilo de descentralización que por la vía de los movimientos regionalistas o federalistas persiga distribuir el poder político del estado. Más bien las demandas descentralizadoras se canalizan de manera gradual y selectiva hacia las regiones y municipios mediante un estilo de descentralización esencialmente administrativo con escasa participación ciudadana y con ausencia de movimientos políticos que provengan desde las regiones.

\section{Referencias Bibliográficas}

Boisier, Sergio (2000), "Chile: la vocación regionalista del gobierno militar". EURE, 26(77):81-107. Santiago.

Boisier, Sergio (2001), La doctrina oculta de a descentralización Chilena. Biblioteca Virtual sobre Gestión Pública. www.top.org.ar/publicac.htm; con- 
sultada el día 15 de diciembre de 2004.

Collier, Simon y Sater, William (1998), Historia de Chile. 1808-1994. Prometeo, Santiago de Chile.

Donoso, Ricardo (1963), Breve Historia de Chile. Editorial EUDEBA, Buenos Aires.

Frías Valenzuela, Francisco (1960), Manual de Historia de Chile. Quinta Edición. Editorial Nacimiento, Santiago, Chile.

Halperin Donghi, Tulio (1986), Historia Contemporánea de América Latina. Alianza Editorial, Madrid.

Pinto, Fernando (1965), La Masonería su Influencia en Chile. Editorial Orbe, Santiago.

Rojas, Rafael (2004), "Conferencia sobre Historia política de América Latina", ofrecida en Flacso-México al programa de doctorado en ciencia política. México.

Salazar, Gabriel y Pinto, Julio (1999), Historia Contemporánea de Chile I, estado, legitimidad, ciudadanía. LOM editores, Santiago de Chile.

Silva, Osvaldo (1995), Breve Historia Contemporánea de Chile. Fondo de Cultura Económica. México DF.

Subsecretaria de Desarrollo Regional y Administrativo (SUBDERE) (2000), "Diagnóstico sobre el proceso de descentralización en Chile". Documento. Santiago de Chile.

Villalobos, Sergio (1987), Breve Historia de Chile. Academia Nacional de la Historia, Caracas, Venezuela.

\section{Leyes y constituciones}

Convención Nacional Constituyente. 1822. "Constitución Política de 1822 del Estado de Chile". Chile.

Congreso Nacional Constituyente. 1823. "Constitución Política del Estado de Chile". Chile.

Asamblea Constituyente. 1828. "Constitución Política de la República de Chile". Chile.

Gran Convención de Chile. 1833. "Constitución Política de 1833". Chile.

Ministerio del Interior. 1925. "Constitución Política de 1925". Chile.

Junta de Corporaciones. 1814. "Reglamento para el gobierno provisorio". Chile.

Comisión Constituyente. 1818. "Proyecto de Constitución Provisoria para el Estado de Chile". Chile.

Ministerio del Interior. 1993. "Ley № 19.175 Orgánica Constitucional sobre Gobierno y Administración Regional", publicada en marzo de 1993. Consultada en la biblioteca de la subsecretaría de desarrollo regional y administrativo del ministerio del interior, Chile.

Ministerio del Interior. 1992. “Ley № 18.695 Orgánica Constitucional de Municipalidades". Chile. 
sultada el día 15 de diciembre de 2004.

Collier, Simon y Sater, William (1998), Historia de Chile. 1808-1994. Prometeo, Santiago de Chile.

Donoso, Ricardo (1963), Breve Historia de Chile. Editorial EUDEBA, Buenos Aires.

Frías Valenzuela, Francisco (1960), Manual de Historia de Chile. Quinta Edición. Editorial Nacimiento, Santiago, Chile.

Halperin Donghi, Tulio (1986), Historia Contemporánea de América Latina. Alianza Editorial, Madrid.

Pinto, Fernando (1965), La Masonería su Influencia en Chile. Editorial Orbe, Santiago.

Rojas, Rafael (2004), "Conferencia sobre Historia política de América Latina", ofrecida en Flacso-México al programa de doctorado en ciencia política. México.

Salazar, Gabriel y Pinto, Julio (1999), Historia Contemporánea de Chile I, estado, legitimidad, ciudadanía. LOM editores, Santiago de Chile.

Silva, Osvaldo (1995), Breve Historia Contemporánea de Chile. Fondo de Cultura Económica. México DF.

Subsecretaria de Desarrollo Regional y Administrativo (SUBDERE) (2000), "Diagnóstico sobre el proceso de descentralización en Chile". Documento. Santiago de Chile.

Villalobos, Sergio (1987), Breve Historia de Chile. Academia Nacional de la Historia, Caracas, Venezuela.

\section{Leyes y constituciones}

Convención Nacional Constituyente. 1822. "Constitución Política de 1822 del Estado de Chile". Chile.

Congreso Nacional Constituyente. 1823. "Constitución Política del Estado de Chile". Chile.

Asamblea Constituyente. 1828. "Constitución Política de la República de Chile". Chile.

Gran Convención de Chile. 1833. "Constitución Política de 1833". Chile.

Ministerio del Interior. 1925. "Constitución Política de 1925". Chile.

Junta de Corporaciones. 1814. "Reglamento para el gobierno provisorio". Chile.

Comisión Constituyente. 1818. "Proyecto de Constitución Provisoria para el Estado de Chile". Chile.

Ministerio del Interior. 1993. "Ley № 19.175 Orgánica Constitucional sobre Gobierno y Administración Regional", publicada en marzo de 1993. Consultada en la biblioteca de la subsecretaría de desarrollo regional y administrativo del ministerio del interior, Chile.

Ministerio del Interior. 1992. “Ley № 18.695 Orgánica Constitucional de Municipalidades". Chile. 